\title{
A domain-general monitoring account of language switching in recognition tasks: Evidence for adaptive control*
}

\author{
ESLI STRUYS \\ Centre for Linguistics, Vrije Universiteit Brussel, Belgium \\ Brussels Institute for Applied Linguistics, Vrije Universiteit, \\ Belgium \\ Centre for Neurosciences, Vrije Universiteit Brussel, Belgium \\ Leiden University Centre for Linguistics, Leiden University, \\ The Netherlands \\ EVY WOUMANS \\ Department of Experimental Psychology, Ghent University, \\ Belgium \\ SOUDABEH NOUR \\ Brussels Institute for Applied Linguistics, Vrije Universiteit, \\ Belgium \\ Centre for Neurosciences, Vrije Universiteit Brussel, Belgium \\ OLGA KEPINSKA \\ Leiden University Centre for Linguistics, Leiden University, \\ The Netherlands \\ Leiden Institute for Brain and Cognition, Leiden University, \\ The Netherlands \\ MAURITS VAN DEN NOORT \\ Brussels Institute for Applied Linguistics, Vrije Universiteit, \\ Belgium \\ Research Group of Pain and Neuroscience, Kyung Hee \\ University, Republic of Korea
}

(Received: November 23, 2016; final revision received: November 17, 2017; accepted: February 19, 2018; first published online 13 June 2018 )

Language switching experience is assumed to have an effect on domain-general control abilities in bilinguals, but previous studies on the relationship between these two variables have generated mixed results. The present study investigated the effects of bilingual experiences on the interaction between language switching and domain-general control. Thirty-two Dutch-French bilingual young adults executed a bilingual categorisation task to assess their language switching abilities and a Simon task to assess domain-general control. The results show that global response times on the Simon task were correlated to the forward switch cost (from L1 to L2); moreover, interestingly, the forward switch cost was found to be related to recent language exposure but not to the age of second language acquisition. We suggest a monitoring account of language switching to integrate the first finding with previous studies and we interpret the second finding as support for the adaptive control hypothesis.

Keywords: language switching, Simon task, bilingualism, cognitive control, bilingual advantage, executive functions

\section{Introduction}

How do bilinguals manage two language systems in their daily interactions? This question has led to a considerable number of studies over the last decade (Kroll \& Bialystok, 2013). In general, these studies show involvement of cognitive control during bilingual language management (Bobb, Wodniecka \& Kroll, 2013). This involvement could lead to superior performance of bilinguals on interference tasks with conflict trials such as the Simon task (for a recent review, see Zhou \& Krott, 2016).

\footnotetext{
* We are grateful to the Research Council of the Vrije Universiteit Brussel for their generous support in funding the present research.
}

Address for correspondence:

Esli Struys, Vrije Universiteit Brussel, Pleinlaan 2, 1050 Elsene, Belgium estruys@vub.ac.be
The main idea behind this bilingual advantage is that there is an overlap between the domains of language and cognitive control and that their constant exposure to two (or more) languages gives bilinguals a training advantage over monolinguals (Garbin, Sanjuan, Forn, Bustamante, Rodriguez-Pujadas, Belloch, Hernandez, Costa \& Avila, 2010; Weissberger, Wierenga, Bondi \& Gollan, 2012). The bilingual advantage is assumed to stem from the daily usage of two languages, both in the monolingual mode, when bilinguals have to suppress interference from the non-target language while speaking or recognising the target language (e.g., Lemhofer, Dijkstra \& Michel, 2004; Starreveld, De Groot, Rossmark \& Van Hell, 2014), and in the bilingual mode, when bilinguals need to be able to 
produce or recognise language switches (e.g., Abutalebi \& Green, 2008; Thomas \& Allport, 2000).

\section{Domain-general control and language control}

A major source of information on the overlap between cognitive and language control comes from experimental studies on single-word language switching (Declerck \& Philipp, 2015). In their seminal study on mixed-language picture naming, Meuter and Allport (1999) found that language switches incur a behavioural cost and that the size of this effect depends on the direction of the language switch with a higher cost for switches from second (L2) into first language (L1) (backward switches) than for switches from L1 into L2 (forward switches). One theoretical account to explain this asymmetry in language switching is derived from the inhibitory control model and suggests that the language switch direction modulates the extent of mental control that is needed to enable the switch (Green, 1998). On a forward switch, much inhibitory control is required to suppress the dominant language. On a subsequent backward switch, this high level of inhibitory control has to be overcome to reactivate the dominant language and this additional reactivation cost is assumed to lead to explain slower performance on a backward switch.

Another theoretical account treats asymmetric switch costs as sequential difficulty effects (Schneider \& Anderson, 2010). In this view, impaired performance on a backward switch is interpreted as a spillover effect of the difficulty of naming pictures in a non-dominant language. As a result of a temporary (so only affecting performance on the immediately following trial) depletion of control resources, the difficulty that is encountered when accessing a weaker mental language set could have an effect on processing the subsequent easier trial. Importantly, the same difficulty is not experienced on both L1-repeat trials and L2-switch trials, because naming images in the most proficient language precedes these trials. The difference between repeat and switch trials is expected to be more modest in L2 than in L1, because L2-repeat trials are preceded by equally difficult L2-trials, and they are thus subject to sequential difficulty. Both theoretical accounts relate the asymmetry in language switching to differences in difficulty or dominance between the languages. As a consequence, both explanations predict less (or no) asymmetry for balanced bilinguals whose two language systems are equally dominant than for unbalanced bilinguals who have one dominant and one non-dominant language system. This prediction has to some extent been confirmed by studies in balanced and unbalanced bilinguals (for an overview, see Reynolds, Schloffel \& Peressotti, 2016).

Beside the usage of the cued picture naming paradigm, other studies have investigated the recognition of language switches by using lexical decision or semantic categorisation tasks. Analogous to the performance on production tasks, the recognition of language switches incurs a behavioural cost with slower response latencies on switch than on repeat trials. But, in contrast to bilingual production tasks, the direction of the switches does not have an effect on performance on recognition tasks (Macizo, Bajo \& Paolieri, 2012; Orfanidou \& Sumner, 2005; Thomas \& Allport, 2000; von Studnitz \& Green, 2002).

One possible reason for this discrepancy between bilingual production and recognition tasks is that only the former entails domain-general inhibitory control, as suggested by the Bilingual Interactive Activation model (Dijkstra \& van Heuven, 2002; van Heuven, Dijkstra \& Grainger, 1998), which attributes switch costs in bilingual word recognition to a domain-specific control mechanism of language activation. It can be assumed that production tasks, but not recognition tasks, involve inhibitory control because only the former generates response competition. The reason for this is that production tasks are typically composed of bivalent stimuli, which means that each stimulus (e.g., a picture) can elicit two responses, or one for each language (for a discussion, see Reynolds et al., 2016). As a result, inhibitory control must be applied to solve this competition between two different responses. Bilingual recognition tasks, on the other hand, are composed of univalent stimuli, meaning that the stimuli (e.g., a word) are coded in a specific language, and thus that these tasks do not necessarily lead to competition between two response sets. This does not mean that modality (recognition or production) and valence (univalent or bivalent) are necessarily conflated, or that it is impossible to untangle which of these two factors is responsible for the asymmetric switch costs. One recent experiment revealed non-symmetric switch costs in bilingual production for both univalent (languagespecific number words such as 'four') and bivalent (language-nonspecific numerals such as '4') stimuli (Reynolds et al., 2016), which suggests that asymmetry is related to response modality instead of stimulus valence.

In most real-life settings, the distinction between bilingual recognition and production may also correspond to a difference in reliance on response competition. In bilingual recognition, verbal or written input will only activate lexical items from one language, except for interlingual homonyms, or words from two languages having the same spelling or pronunciation but a different meaning (e.g., Durlik, Szewczyk, Muszynski \& Wodniecka, 2016); in bilingual production, however, the initial stage of conceptual preparation (Levelt, Roelofs \& Meyer, 1999) may lead to at least two lexical items (one for each language) competing for activation, except in case of identical cognates or words from two languages with the 
same meaning and spelling or pronunciation (e.g., Costa, Santesteban \& Cano, 2005).

A more direct line of evidence on the interaction between domain-general control and language switching comes from studies in which the same participants execute tasks of domain-general control and language switching. Analogous to the ongoing debate on bilingual advantages in cognitive control (e.g., von Bastian, Souza \& Gade, 2016), these studies have generated mixed results. On the one hand, some studies have suggested strong domaingeneral involvement in language control by showing that groups with superior language switching abilities or a higher switching frequency score better on tasks of domain-general control (Festman \& Munte, 2012; Prior \& Gollan, 2011; Verreyt, Woumans, Vandelanotte, Szmalec \& Duyck, 2016; Woumans, Ceuleers, Van der Linden, Szmalec \& Duyck, 2015); that inhibitory control predicts switch costs in picture naming (Linck, Schwieter \& Sunderman, 2012); and that training on either domain-general or domain-specific control transfers into performance in the other domain (Liu, Liang, Dunlap, Fan \& Chen, 2016; Prior \& Gollan, 2013; Zhang, Kang, Wu, Ma \& Guo, 2015). On the other hand, some studies have suggested limited or no involvement of domain-general control abilities by showing that the magnitude of switch costs on mixed-language picture naming and non-linguistic task switch paradigms are not related to each other (Branzi, Calabria, Boscarino \& Costa, 2016; Calabria, Hernandez, Branzi \& Costa, 2012; Magezi, Khateb, Mouthon, Spierer \& Annoni, 2012); that domain-general control abilities are not related to grammaticality manipulations in mixed-language connected speech production (Gollan \& Goldrick, 2016); and that domain-general control mechanisms can be bypassed if switching only occurs when a word is more accessible in the other language (Kleinman \& Gollan, 2016). In a similar vein, three recent studies suggest that aging has a more profound impact on domain-specific than on domain-general control abilities (Calabria, Branzi, Marne, Hernandez \& Costa, 2015; Ivanova, Murillo, Montoya \& Gollan, 2016; Weissberger et al., 2012). Moreover, bilingual aphasia turns out to have a different impact on domain-general control, as measured by a flanker task and domain-specific control (Gray \& Kiran, 2016).

Importantly, the studies mentioned above on the interaction between domain-general and domain-specific control have so far mostly focused on the overlap between these two types of inhibitory control as measured by the conflict size on non-linguistic interference tasks and switch costs in language switching paradigms, respectively. However, bilingual advantages in cognitive control tend to manifest themselves more generally on global performance (as a reflection of superior conflict monitoring skills) than specifically on conflict trials (as a reflection of superior inhibitory control skills) (Costa, Hernandez, Costa-Faidella \& Sebastian-Galles, 2009; Hilchey \& Klein, 2011). Therefore, it is essential not only to include measures of language production that generate language competition at the response level and that require inhibitory control to solve this competition, but also measures of language recognition that involve extensive monitoring needed to assess which language system to access.

\section{The effects of language experience on language switching and cognitive control}

Language proficiency is one of the most important factors to explain asymmetric switch patterns in mixed-language production tasks. Most studies that reported higher backward than forward switch costs in picture naming had unbalanced bilinguals as participants (Costa \& Santesteban, 2004; Costa, Santesteban \& Ivanova, 2006; Fink \& Goldrick, 2015; Jackson, Swainson, Cunnington \& Jackson, 2001; Meuter \& Allport, 1999; Philipp, Gade \& Koch, 2007; Verhoef, Roelofs \& Chwilla, 2009) or tested highly proficient bilinguals in a low proficient third language or a newly learnt language (Costa et al., 2006; Martin, Strijkers, Santesteban, Escera, Hartsuiker \& Costa, 2013). These findings suggest that initially higher inhibitory control requirements related to managing two or more language systems with huge differences in proficiency levels disappear with increasing proficiency in the low proficient language. Interestingly, the effect of increasing L2 proficiency on asymmetry in language switching seems to extend beyond the linguistic domain: bilinguals with a higher L2 proficiency can switch more easily from a more difficult to an easier task set as compared to bilinguals with low L2 proficiency (Tse \& Altarriba, 2015); besides, L2 proficiency has been associated with enhanced conflict resolution and working memory capacity (Tse \& Altarriba, 2014). These findings are in line with some recent studies suggesting that enhanced performance on domain-general control is related to higher second language proficiency or balanced bilingualism (Singh \& Mishra, 2015; Yow \& Li, 2015; but also see von Bastian et al., 2016).

Measures of language proficiency in each of the languages of a bilingual may not be sufficient to capture the complex nature of bilinguals' language usage (Yang, Hartanto \& Yang, 2016). The variability in language switching abilities may be related to specific patterns of language use. The adaptive control hypothesis (Green \& Abutalebi, 2013) suggests varying language control requirements for the different conversational contexts that bilinguals may encounter in their daily language use. This hypothesis has been tested with bilinguals within singlelanguage and dual-language contexts, showing smaller switch costs in task-switching paradigms for bilinguals 
who use their two languages in the same conversational contexts (Hartanto \& Yang, 2016). This effect is possibly mediated by switching frequency because language switches are rare when bilinguals use their two languages in different contexts. In one study where three groups of bilinguals with divergent language switching experiences were compared on cognitive control to a group of monolinguals, the balanced switching bilinguals group turned out to outperform the other non-switching and unbalanced bilingual groups, who did not differ from each other (Verreyt et al., 2016). High adaptability of language control can also be assessed using language tasks. On a trilingual picture naming task, Babcock and Vallesi (2015) found different patterns of $n-2$ repetition costs for the three languages in the four groups they examined, which was assumed to reflect the divergent interactional contexts in which these languages were used by these different groups. Even higher adaptability of language control was found in a study on the effect of domain-general inhibitory control training on asymmetry of language switches in production: only after six training sessions over a oneweek period, asymmetry in language switching turned into symmetric language switches (Liu et al., 2016). Again, it is important to stress that studies on the effect of bilingual experience on the development of language control have so far only included production tasks, but no recognition tasks.

\section{The present study}

The present study aims to investigate the interaction between the recognition of language switches and domaingeneral cognitive control abilities in a group of bilinguals with varying levels of second language proficiency and degrees of recent language exposure. Previous studies have suggested that inhibitory control is not involved in recognition tasks due to the absence of asymmetric language switching or slower responding on forward than on backward switch trials (Macizo et al., 2012). However, inhibitory control is only one of the three processes that are part of domain-general control, next to shifting and updating or monitoring (Miyake, Friedman, Emerson, Witzki, Howerter \& Wager, 2000). Whereas bilingual production tasks require inhibitory processes to solve competition between lexical items from both languages at the response level, it can be assumed that bilingual recognition tasks have high monitoring requirements at the input level because stimuli are presented in both languages and participants thus constantly have to monitor which language system to access in order to respond accurately to the task at hand. The theoretical motivation of this study lies in the assumption that different control mechanisms are at play in bilingual recognition tasks (language input monitoring) compared to bilingual production tasks (response competition) and that this will result in significant correlations with different measures of domain-general control for recognition (monitoring) and production tasks (inhibition) in two languages.

This theoretical motivation has driven our choice to select an interference task (i.e., the Simon task) to measure domain-general control, because this type of task allows for measuring processes of monitoring (indexed by global performance) and inhibition (indexed by the effect of congruency) at the same time - for a review on using measures of interference tasks such as the Simon task with bilingual participants, see Hilchey and Klein, 2011. The congruency or Simon-effect is caused by stimulusresponse interference on incongruent trials, which means that the stimuli on these trials automatically generate a response that must be suppressed (Simon \& Rudell, 1967). Throughout the entire task, the participant has to monitor the possibility of an upcoming stimulus-response conflict because congruent and incongruent trials are evenly distributed and switches are unpredictable. As such, the usage of an interference task gives us the possibility to assess to which of these two processes performance on a bilingual recognition task is most related. One additional motivation for choosing an interference task is that it allows for testing the relationship between switch directionality effects in bilingual language control and domain-general control. Previous research on interference tasks has revealed that the behavioural effects of difficult (or incongruent) trials are smaller when these trials are preceded by another difficult trial than when they follow an easy (or congruent trial) (Blais, Stefanidi \& Brewer, 2014; van Maanen \& van Rijn, 2010). Drawing an analogy with language switching, this effect may be considered as a forward switch cost (from an easy to a difficult trial). To test the overlap between various measures of bilingual language control and domain-general control, we will examine if switch directionality effects (both forward and backward switch costs) in both tasks are related to each other.

The first research question we intend to investigate with this study is to what extent language switch costs in either direction (from L1 to L2 and from L2 to L1) on a categorisation task correlate with cognitive control performance. Based on the Inhibitory Control Model (Green, 1998) and the Bilingual Interactive Activation Model (Dijkstra \& van Heuven, 2002), we expect switch costs on the categorisation task not to be related to the conflict or congruence effect in the Simon task (as a reflection of inhibitory skills) because, unlike production, bilingual categorisation does not involve response competition (Macizo et al., 2012). Instead, we expect switch costs on the categorisation task to be selectively correlated to global performance on the interference task (as a reflection of monitoring skills), which is in line with the bilingual monitoring advantage or the observation of decreased global response times 
for bilinguals on interference tasks (Costa et al., 2009). Because it is more effortful to recognise lexical items from a non-dominant than from a dominant language, the behavioural effects of the monitor's efficiency are expected to manifest themselves rather on forward switches (from L1 to L2) than on backward switches (from L2 to L1).

Our second research question is to what extent individual language background characteristics such as second language proficiency, onset age of second language acquisition, and recent language exposure contribute to performance on a bilingual language control task. In line with the adaptive control hypothesis (Green \& Abutalebi, 2013), we expect that individuals with higher proficiency or longer exposure to a second language may show facilitation in language switching indicated by smaller switch costs on the bilingual categorisation task.

\section{Materials and methods}

\section{Participants}

A total of 32 Dutch-French bilingual young adults from the Dutch-medium Vrije Universiteit Brussel in Belgium (14 females; mean age $=20.6$ years; $S D=0.5$ years) were selected for this study. All participants indicated Dutch as their first language (L1) and French as their second language (L2). They were all first-year Bachelor's students in an applied linguistics programme with two languages, including French and one other language (Dutch, English, German or Spanish). They were tested at the end of the second semester, after eight months of study. During the weeks of lecture, they had had at least six hours of instruction in French. The other lectures were taught in Dutch (general courses in linguistics) or in the other language of the programme. Students with lower proficiency in French at the start of the programme received additional instruction in that language to catch up with their peers who had higher proficiency in French. As a result, second language proficiency did not automatically imply higher rates of recent language exposure. All participants had also learnt English from age 12 at school. At the point of examination, for all participants Dutch was the principal language they had been using and still used for education. All participants completed an adapted version of the Language Experience and Proficiency Questionnaire (Marian, Blumenfeld \& Kaushanskaya, 2007) in Dutch including questions about the number of languages they spoke, their onset ages of language acquisition for each of these languages, self-reported language proficiency on a 5-point scale, and exposure to their languages in the twelve months preceding the time of investigation (in percentages). Paired samples T-tests on the whole test population revealed highly significant differences with large effect sizes between the first and
Table 1. Language background characteristics of participants

\begin{tabular}{|c|c|c|}
\hline & L1-Dutch & L2-French \\
\hline \multicolumn{3}{|c|}{ Onset age of acquisition } \\
\hline $\mathrm{M}(\mathrm{SD})$ & $0.00(0.00)$ & $3.47(4.59)$ \\
\hline Median (range) & $0(0-0)$ & $0(0-10)$ \\
\hline \multicolumn{3}{|c|}{ Self-rated proficiency } \\
\hline $\mathrm{M}(\mathrm{SD})$ & $4.94(0.23)$ & $3.86(0.76)$ \\
\hline Median (range) & $5(4-5)$ & $4(3-5)$ \\
\hline \multicolumn{3}{|l|}{ Recent exposure } \\
\hline $\mathrm{M}(\mathrm{SD})$ & $51.22(4.54)$ & $36.44(9.74)$ \\
\hline Median (range) & $50(41-62)$ & $36(22-53)$ \\
\hline \multicolumn{3}{|l|}{ Verbal fluency } \\
\hline $\mathrm{M}(\mathrm{SD})$ & $*$ & $8.00(3.48)$ \\
\hline Median (range) & $*$ & $8(3-15)$ \\
\hline
\end{tabular}

Note: Onset age of acquisition is given in years. Self-rated proficiency was given on a 5-point scale, ranging from 1 (not proficient) to 5 (native proficiency), for each language ability separately (listening, speaking, reading and writing). Only the mean score is given. Recent exposure to each of the languages during the year preceding the time of investigation was given in percentages. Verbal fluency was assessed as number of words per minute. ${ }^{*}$ Due to language order effects in the verbal fluency task, only L2 scores are reported and used for further analysis.

second language with regards to self-reported language proficiency, $t(31)=7.54, p<.001, d=1.33$, and language exposure, $t(31)=6.15, p<.001, d=1.09$. Language background information on the group of participants as a whole is given in Table 1.

\section{Single-language verbal fluency task}

This task was included to report an objective score on the participants' productive language ability in their second language. Participants were instructed to name as many words as possible that start with a given phoneme in a one-minute period. This task had two conditions: Dutch (or L1) and French (or L2). The order of both conditions was counterbalanced across participants. Three phonemes with an equal distribution as onset sound in Dutch and French words were selected from the CELEX database (Baayen, Piepenbrock \& Van Rijn, 1993): /1/, /t/ and $/ \mathrm{m} /$. These three phonemes could be presented to the participants in six different orders. The order of presentation was randomly distributed across participants. All spoken instructions were digitally prerecorded by a Dutch-French bilingual speaker and they were administered to the participants through headphones with a microphone attached. Only L2 scores are reported and used for further analyses because previous research has shown that fluency in L1 suffers if it is performed after L2 in exactly the same version of the verbal fluency task used in this study (Van Assche, Duyck \& Gollan, 2013). Importantly, the same study revealed that non-dominant 
language production was not affected by prior production of words from the other language. Descriptive statistics about the L2 scores on this task are given in Table 1.

\section{Bilingual categorisation task}

The stimuli of the bilingual categorisation task were 156 nouns, that were equally divided over two factors: animacy and language; each taking two levels: animate and inanimate for animacy; and Dutch and French for language. The 156 stimuli thus consisted of 39 Dutch animate nouns; 39 Dutch inanimate nouns; 39 French animate nouns; and 39 French inanimate nouns. All words were selected from the CELEX database (Baayen et al., 1993) and were matched across languages and categories for word length and frequency. Cognates between languages were not included. The stimuli of this task did not contain any translation equivalents, so all presented words were different for the two language conditions. The task was designed such that language switches were unpredictable and that the same trial type did not occur more than three times in a row. Participants were instructed to respond as quickly as possible to the animacy of the stimulus with a left or right button press. Stimulus-response mapping was counterbalanced across participants: animacy of the stimulus was for half of them linked to a left button press and for the other half to a right button press. Each stimulus was preceded by a fixation cross which remained in the centre of the screen for 500 milliseconds. The stimuli were presented in black Courier font, size 36, for up to 2000 milliseconds in the centre of a white screen or until the participant responded. Apart from the first four trials, which were removed from further analysis, the task contained 76 language repeat trials and 76 language switch trials.

\section{Simon task}

The stimuli of the Simon task (Simon \& Rudell, 1967) were a red and a green square that were presented at the left or right side of the computer screen. The total number of trials was 156 , equally divided according to the colour and location of the stimulus: 39 trials with a red square appearing on the left; 39 trials with the same square appearing on the right; 39 trials with a green square appearing on the left; and 39 trials with the same square appearing on the right. The width of the squares was $10 \%$ of the width of the screen and the centre of the squares was positioned vertically on the centre line of the screen and horizontally at $15 \%$ and $85 \%$ of the width of the screen. Participants were instructed to respond as quickly as possible to the colour of the stimulus with a left or right button press, ignoring the location of the stimulus. Stimulus-response mapping was counterbalanced across participants: a green stimulus was for half of them linked to a left button press and for the other half to a right button press. Each stimulus was preceded by a fixation cross which remained in the centre of the screen for 500 milliseconds. The stimuli were displayed in the centre of a black screen for up to 2000 milliseconds or until the participant responded. On congruent trials (78 trials), the location of the stimulus overlapped with the location of the button press; on incongruent trials (78 trials), the location of the stimulus did not overlap with the location of the button press. The task was designed in such a way that the congruence of the next trial was unpredictable and that the same trial type did not occur more than three times in a row.

\section{Procedure}

The bilingual categorisation task and the Simon task were programmed in E-Prime 2 (Psychology Software Tools, Pittsburgh, PA) and implemented on a Dell Latitude E6500 with a 15.4-inch screen. All participants were tested individually in a soundproof experimental cabin on campus. All participants started with the verbal fluency task. The order of the two other tasks was counterbalanced across participants. A practice block of ten trials preceded both experimental tasks to ascertain that the participants had understood the task instructions. All participants obtained the self-defined cutoff score of $80 \%$ and could proceed to the actual experimental task.

\section{Results}

\section{Bilingual categorisation task}

Response times (in milliseconds) and accuracy scores (one for correct trial and zero for incorrect trial) were collected for all 152 trials of this task. Both by-subject (F1) and by item (F2) analyses were performed. Mean accuracy scores are reported in percentages as a ratio of correct trials to the total number of trials. Response times on incorrect trials and on correct trials with a response time above or below 2.5 standard deviations from the individual mean were removed from further analysis. One-sample Kolmogorov-Smirnov tests were conducted on response times and accuracy scores to test for normality.

A two-way analysis of variance was conducted on mean response times and mean accuracy scores with Language and Type of trial as the within-subject variables, each with two levels (Dutch and French for Language; repeat and switch for Type of trial). We expected main effects of these two variables with higher response times for L2 than L1; and a general switch cost. The interaction effect between these two variables was tested to assess the symmetry of switch costs, with a significant interaction effect taken as an indicator of asymmetric switch costs 


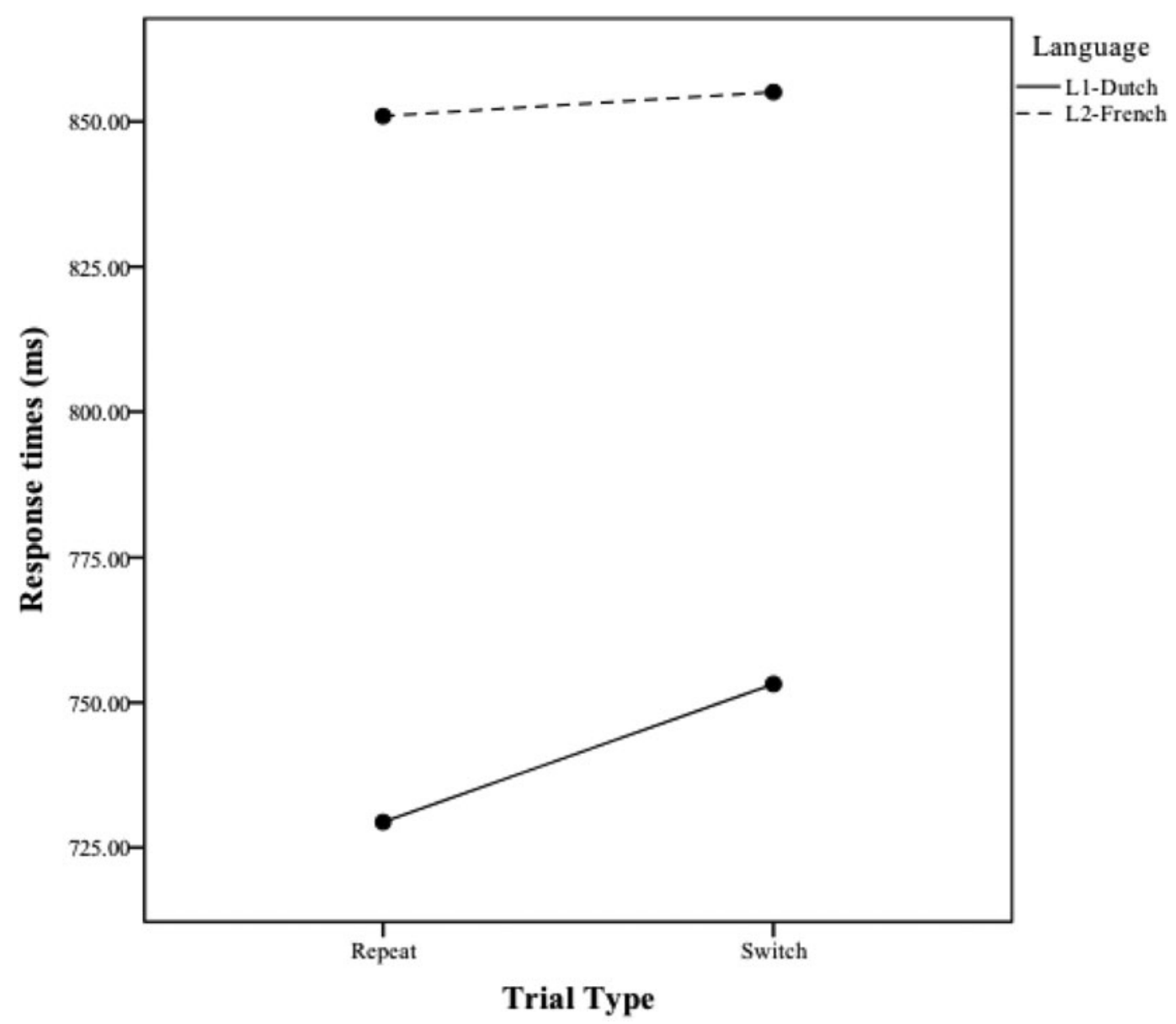

Figure 1. Mean response times (in milliseconds) on the bilingual categorisation task as a function of language (Dutch or French) and trial type (repeat or switch).

and no significant interaction effect as an indicator of symmetric switch costs.

As for the by-subject analyses (F1), we found a highly significant main effect of Language on the response times (see Figure 1), $F 1(1,31)=44.10, p<.001, \eta \mathrm{p} 2=.59$, with higher response times on French trials $(M=853.04$; $S D=146.55)$ than on Dutch trials $(M=741.30 ; S D$ $=131.33)$. We also found a significant main effect of Type of trial, $F 1(1,31)=6.93, p=.01, \eta \mathrm{p} 2=.18$, with higher response times on switch trials $(M=804.15$; $S D=142.76)$ than on repeat trials $(M=790.16 ; S D$ $=135.12)$. We found no significant interaction effect between the variables Language and Type of trial, F1(1, $31)=1.57, p$ ns. The by-item analyses (F2) on response times confirmed the $\mathrm{F} 1$ analyses, with a highly significant main effect of Language, $F 2(1,151)=225.53, p<.001$, $\eta \mathrm{p} 2=.60$; a significant main effect of Type of trial, F2(1, $151)=5.53, p<.05, \eta p 2=.04 ;$ and no significant interaction effect between Language and Type of trial, $F 2(1,151)=1.06, p$ ns.
As it has been recommended to analyse categorical data that are collected from psycholinguistic tasks with logistic mixed-effects regression modelling (LMER) rather than with analysis of variance (e.g., Ivanova, Salmon \& Gollan, 2014; Jaeger, 2008), we implemented such a model with Language and Trial type as fixed predictors, and Subject and Item as random predictors in the statistical software R (version 3.3.3; The R Foundation for Statistical Computing, 2017). The model had random intercepts and slopes for Subject, and random intercepts for Item. We used contrast coding for the fixed predictors, which means that both languages and types of trial were assigned the numerical values of -0.5 (Dutch for Language, and repeat for Type of trial) and 0.5 (French for Language, and switch for Type of trial). The results from the analysis of variance on the same data can be found in Appendix 1.

The results from the LMER analyses can be found in Table 2. Only the main effect of Language turned out to be statistically significant, with lower accuracy scores on French trials $(M=83.37 ; S D=11.41)$ than on Dutch trials 


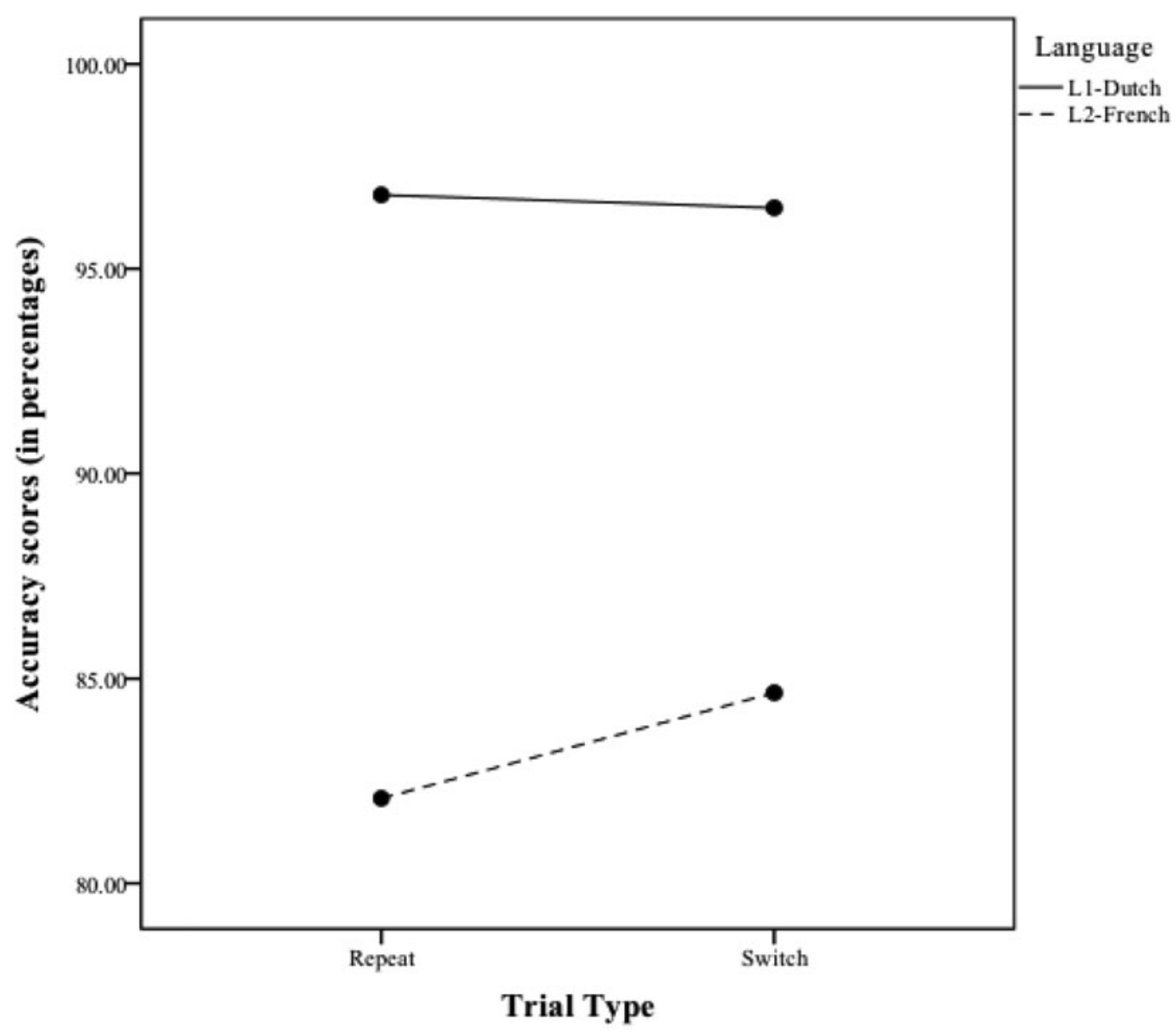

Figure 2. Mean accuracy scores (in percentages) on the bilingual categorisation task as a function of language (Dutch or French) and trial type (repeat or switch).

Table 2. Results of LMER analyses on accuracy data from the mixed-language categorisation task.

\begin{tabular}{lccrc}
\hline \hline Fixed predictor & Estimate & $S E$ & Wald Z & $p$ \\
\hline Language & -.13 & .02 & -6.57 & $<.001$ \\
Type of trial & -.02 & .01 & 1.12 & .27 \\
Language $^{*}$ Type of trial & .03 & .02 & 1.32 & .19 \\
\hline \hline
\end{tabular}

$S E=$ standard error.

$(M=96.65 ; S D=2.90)$ (see Figure 2). Neither the main effect of Trial Type nor the interaction effect between both variables turned out to be significant.

To further investigate the effects of switch directionality, we calculated backward and forward switch costs in terms of response times and accuracy scores. The backward switch cost of each individual participant was calculated by subtracting mean response times or error rates on L1-repeat trials from the same measures on L1-switch trials; analogously, the forward switch cost was calculated by subtracting mean response times or
Table 3. Mean backward and forward switch costs on the categorisation and Simon task in milliseconds with standard deviations between brackets.

\begin{tabular}{llr}
\hline \hline $\begin{array}{l}\text { Bilingual } \\
\text { categorisation } \\
\text { task }\end{array}$ & Backward switch cost & $23.79(38.72)$ \\
Simon task & & $4.13(65.17)$ \\
& Backward switch cost & $30.51(21.41)$ \\
& Forward switch cost & $28.15(16.64)$ \\
\hline \hline
\end{tabular}

error rates on L2-repeat trials from the same measures on L2-switch trials. The descriptive statistics of these two measures are given in Table 3 and 4.

A paired samples T-test on backward and forward switch costs was added to test the null hypothesis of no difference between both switch types. The null hypothesis could not be rejected, both for response times, $t(31)=$ $1.25, p$ ns., and for accuracy, $t(31)=1.90, p$ ns.

We conducted correlational analyses between the switch costs. Significant correlations were only found 
Table 4. Mean backward and forward switch costs on the categorisation and Simon task in percentages of correct responses with standard deviations between brackets.

\begin{tabular}{llr}
\hline \hline $\begin{array}{l}\text { Bilingual } \\
\text { categorisation } \\
\text { task }\end{array}$ & Backward switch cost & $0.32(3.62)$ \\
Simon task & Backward switch cost & $-2.58(8.32)$ \\
& Forward switch cost & $2.79(3.49)$ \\
\hline
\end{tabular}

between backward and forward switch costs in terms of response times, $r(32)=-.43, p<.05$, and between backward switch costs in terms of response times and accuracy scores, $r(32)=-.36, p<.05$, which may be indicative of a speed-accuracy trade-off when it comes to switching from L2 into L1. No other correlations were significant.

\section{Simon task}

Response times (in milliseconds) and accuracy scores (one for correct trial and zero for incorrect trial) were collected for all 156 trials of this task. Mean accuracy scores are reported in percentages as a ratio of correct trials to the total number of trials. Response times on incorrect trials were removed from further analysis. Onesample Kolmogorov-Smirnov tests were conducted on response times and accuracy scores to test for normality.

The statistical analysis of the Simon task was performed as closely as possible to that of the bilingual categorisation task. Hence, a two-way analysis of variance was conducted on mean response times and mean accuracy scores with Congruency and Type of trial as the within-subject variables, each with two levels (congruent and incongruent for Congruency; repeat and switch for Type of trial). We expected a main effect of Congruency (Simon \& Rudell, 1967). The second within-subject variable was added to our model to assess potential similarities between the language catagorisation task and the Simon task. If domain-general inhibitory control as measured by the Simon task is a good proxy of domain-specific (language) control on a bilingual categorisation task, switching back and forth between easier (congruent) trial and more difficult (incongruent) trials may be similar to switching between languages with varying proficiency levels, and thereby generating comparable switch costs. In addition, the interaction effect between both within-subject variables was added to explore potential similarities between the direction of congruence switches in the Simon task and the direction of language switches in the bilingual categorisation task.

With respect to the response times, we found a highly significant effect of Congruency, $F(1,31)=29,21$, $p<.001, \eta \mathrm{p} 2=.49$, with higher response times on incongruent trials $(M=437.62 ; S D=53.24)$ than on congruent trials $(M=423.08 ; S D=56.19)$. We also found a highly significant effect of Type of trial, $F(1,31)$ $=121.90, p<.001, \eta \mathrm{p} 2=.80$, with higher response times on switch trials $(M=445.01 ; S D=56.64)$ than on repeat trials $(M=415.68 ; S D=52.79)$. We found no significant interaction effect between the variables Congruency and Type of trial, $F(1,31)=.31, p$ ns.

The accuracy scores on the Simon task were not normally distributed due to a ceiling effect. Therefore, two Wilcoxon signed-rank tests were conducted, first comparing accuracy scores on congruent and incongruent trials (effect of Congruency); then comparing accuracy scores on switch and repeat trials (effect of Type of trial). We found a significant effect of Congruency, $Z=4.33, p<$ .001 , with a higher median accuracy score for repeat trials (100; range: 96-100) than for switch trials (98; range: 88$100)$. We did not find a significant effect of Congruency, $Z=.82, p \mathrm{~ns}$.

We further investigated the effects of switch directionality in the Simon task by calculating forward and backward switch costs, again analogous to the analysis of the bilingual categorisation task, and in line with the observed main effects of switch on mean response times and accuracy scores of the Simon task. As for response times, the backward switch cost of each individual participant was calculated by subtracting mean response times on congruent-repeat trials from mean response times on congruent-switch trials; analogously, the forward switch cost was calculated by subtracting mean response times on incongruent-repeat trials from mean response times on incongruent-switch trials. As for accuracy scores, the backward switch cost of each individual participant was calculated by subtracting mean accuracy scores on congruent-switch trials from mean accuracy scores on congruent-repeat trials. The forward switch cost was calculated by subtracting mean accuracy scores on incongruent-switch trials from mean accuracy scores on incongruent-repeat trials. One sample T-tests against zero revealed that the backward switch costs were significant with large effect sizes in terms of response times, $t(31)=8.06, p<.001, d=1.42$, and accuracy scores, $t(31)=4.52, p<.001, d=0.80$; the forward switch costs were also significant with moderate to large effect sizes in terms of response times, $t(31)=9.57, p<$ $.001, d=1.69$, and accuracy scores, $t(31)=3.49, p<$ $.01, d=0.62$.

\section{Correlations among measures of language and domain-general (cognitive) control}

To test for dependency between measures of domainspecific (language) control and domain-general control, we conducted Pearson's correlational analyses among 
Table 5. Correlation coefficients among measures of domain-specific (language) control and domain-general (cognitive) control in terms of speed of processing.

\begin{tabular}{|c|c|c|}
\hline Measure of language control & Measure of cognitive control & Correlation coefficient \\
\hline \multirow[t]{5}{*}{ Global RT } & Global RT & $.68^{* *}$ \\
\hline & Congruency difference & -.33 \\
\hline & Switch-cost difference & -.01 \\
\hline & Backward switch cost & .11 \\
\hline & Forward switch cost & .08 \\
\hline \multirow[t]{5}{*}{ Language difference } & Global RT & .03 \\
\hline & Congruency difference & .12 \\
\hline & Switch-cost difference & -.16 \\
\hline & Backward switch cost & .07 \\
\hline & Forward switch cost & -.27 \\
\hline \multirow[t]{5}{*}{ Switch-cost difference } & Global RT & $.46^{* *}$ \\
\hline & Congruency difference & .14 \\
\hline & Switch-cost difference & .17 \\
\hline & Backward switch cost & $.42 *$ \\
\hline & Forward switch cost & -.05 \\
\hline \multirow[t]{5}{*}{ Backward switch cost } & Global RT & -.01 \\
\hline & Congruency difference & -.07 \\
\hline & Switch-cost difference & .08 \\
\hline & Backward switch cost & .21 \\
\hline & Forward switch cost & .24 \\
\hline \multirow[t]{5}{*}{ Forward switch cost } & Global RT & $.42^{*}$ \\
\hline & Congruency difference & .16 \\
\hline & Switch-cost difference & .12 \\
\hline & Backward switch cost & .26 \\
\hline & Forward switch cost & -.19 \\
\hline
\end{tabular}

L2 $=$ second language; ${ }^{*} p<.05 ;{ }^{* *} p<.01 ; N=32$

response times and accuracy scores on the bilingual categorisation task and the Simon task. We distinguish between measures at three levels: first, we took into account global response times on each task; second, we looked at language and switch-cost differences (for the bilingual categorisation task) and at congruency and switch-cost differences (for the Simon task); third, we considered the forward/backward switch costs for both tasks. Language differences on the bilingual categorisation task were calculated by subtracting mean response times (or accuracy rates) on L1 trials from the same measure on L2 trials. Congruency differences on the Simon task were calculated by subtracting mean response times (or accuracy rates) on congruent trials from the same measure on incongruent trials. Switchcost differences were calculated by subtracting mean response times (or accuracy rates) on repeat trials from the same measure on switch trials for both tasks. In total, we conducted correlational analyses on five measures of the bilingual categorisation task and the equivalent five measures of the Simon task, which resulted in 25 (5 times 5) correlation coefficients for response times and for accuracy scores. The results of the analyses on the response times are given in Table 5. The same correlational analyses were conducted on the accuracy scores, but none of the correlations turned out to be significant.

\section{Correlations among measures of language control and language background variables}

To test the adaptive control hypothesis, we conducted Pearson's correlational analyses among measures of language control and language background characteristics (see Table 1). Correlation coefficients are given in Table 6.

As all our participants also reported proficiency in English as their third language, we conducted Pearson's correlational analyses between their selfreported proficiency in that language and their exposure to it, and the measures of language control to assess if, 
Table 6. Correlation coefficients among language background characteristics and measures of domain-specific (language) control in terms of speed of processing.

\begin{tabular}{llc}
\hline \hline Measure of language control & Language background characteristic & Correlation coefficient \\
\hline Global RT & Onset age of L2 acquisition & .32 \\
& Self-reported L2 proficiency & .05 \\
L2 exposure & -.15 \\
L2 verbal fluency & -.21 \\
Language difference & Onset age of L2 acquisition & $.70^{* *}$ \\
& Self-reported L2 proficiency & $-.64^{* *}$ \\
Switch-cost difference & L2 exposure & $-.77^{* *}$ \\
& L2 verbal fluency & $-.37^{*}$ \\
Backward switch cost & Onset age of L2 acquisition & .05 \\
& Self-reported L2 proficiency & -.29 \\
& L2 exposure & $-.35^{*}$ \\
& L2 verbal fluency & -.02 \\
Forward switch cost & Onset age of L2 acquisition & .18 \\
& Self-reported L2 proficiency & .11 \\
& L2 exposure & .22 \\
& L2 verbal fluency & .14 \\
\hline \hline
\end{tabular}

L2 $=$ second language; ${ }^{*} p<.05 ;{ }^{* *} p<.01 ; N=32$

and to what extent, their third language skills could have impacted their language control skills, but none of these correlations achieved significance.

\section{Discussion}

The present study investigated domain-general control involvement in language switching on a bilingual categorisation task. A consideration of the relationship between second language proficiency, onset age of second language acquisition, and recent language exposure and language control measures tested the adaptive control hypothesis. The results showed that domain-general control was critically involved in switches from the dominant into the non-dominant language. Moreover, the size of these forward language switches depended on recent L2 exposure and not on the onset age of acquisition or second language proficiency, which is indicative of short-term adaptability of language control to changing demands from the language environment.

\section{Domain-general control and language switching}

The present study used a bilingual categorisation task with unpredictable language switches to assess language switching in bilingual participants. In line with all studies on non-voluntary language switching (e.g., Gollan \& Ferreira, 2009; Meuter \& Allport, 1999), this paradigm generated switch costs in processing speed. These switch costs were symmetric, which means no differences in the size of the language switches were seen between backward (switches into L1) and forward (switches into L2) switches. This finding is in line with all previous studies on language switching in categorisation tasks (for an overview, see Reynolds et al., 2016) and it adds to the idea that the processes of producing and recognising language switching are fundamentally different - in that the former generates (in some instances) asymmetric switches, while the latter results in switching symmetry. Possibly, this difference can be related to the absence of competition between response sets on language switches in tasks with univalent stimuli (see Green, 1998).

Unlike previous studies on language switching in recognition tasks (e.g., Macizo et al., 2012; Orfanidou \& Sumner, 2005), the present study added a measure of domain-general inhibitory control to the test battery in order to investigate the interaction between language switching and domain-general control abilities. Crucially, we reported a dependency between global response times on a Simon task and several measures of the bilingual 
categorisation task. A relationship was found between overall performance (in terms of global response times) on the bilingual categorisation task and on the Simon task, which suggests that these two tasks rely on similar sustained control requirements. Indeed, both tasks share a few characteristics: they are composed of an equal number of easy and more difficult trials, and they require switching between these two trial types on an unpredictable basis. This finding is important, because the bilingual advantage in cognitive control manifests itself more often on global response times than on specific trial types of interference or conflict tasks (Hilchey \& Klein, 2011). The observed dependency between a measure of sustained language control and global response times of a domain-general task of cognitive control suggests that this bilingual advantage on global response times is related to the efficiency of recognising language switches.

More fine-grained analyses allowed us to achieve a more detailed understanding of this interaction: first, the global response times on the Simon task were specifically related to switch costs and not to differences between L1 and L2 processing (main effect of language); second, the global response times were specifically related to forwardand not to backward-switches, which means that people who are globally faster on the Simon task only have smaller costs when they switch into their L2 than into their L1. These two findings imply that sustained domaingeneral control abilities do not attenuate the effect of differences in language proficiency levels, as measured by the main effect of language, but that they rather have an impact on the ability to shift between two mental language sets. More specifically, sustained domain-general control abilities seem to be related to the ability to shift from a dominant to a weaker mental language set.

Apart from these significant correlations between language control and domain-general cognitive control, we could not find any relationship between the congruency effect in the Simon task and measures of language control in recognition. As such, the results from our study are different from those of a previous study on the interaction between inhibitory control and switch costs in bilingual picture naming that found significant contributions from the size of the Simon effect to switch costs from and into L1 (Linck et al., 2012). Again, we suggest that the absence of competition between response sets on language switches in a recognition task could explain this difference between producing and recognising language switches. At the same time, we acknowledge that many studies on bilingual language production could not find a significant correlation with measures of domain-general inhibitory control as indexed by switch costs in a taskswitching paradigm (Declerck \& Philipp, 2015) and it remains open for further study if these differences between studies might be related to the specific tasks being used for testing this relationship (e.g., Simon task versus a task-switching paradigm) or if they might represent a crucial difference between bilingual language production and recognition. With regards to the ongoing discussion on domain-generality of control abilities (e.g., Calabria et al., 2012; Gollan \& Goldrick, 2016), our results prompt a nuanced view on the matter. On the one hand, the findings from the present study are in line with previous studies that could not find any correlation between equivalent control measures in domain-specific linguistic and domain-general cognitive tasks (e.g., Calabria et al., 2012; Magezi et al., 2012), even if these two tasks are designed in such a way that they share as many characteristics as possible (e.g., Branzi et al., 2016). Indeed, we did not detect a dependency between switch costs in the bilingual categorisation task and in the Simon task; nor did we find any correlation between backward and forward switch costs in these two tasks. On the other hand, our findings are compatible with studies that show domain-general involvement in language switching performance (e.g., Verreyt et al., 2016; Woumans et al., 2015). Interestingly, one previous study reported that mixing costs on a productive language switching task were only correlated to global response times of the Simon task (Paap \& Greenberg, 2013), a finding which is comparable to the one reported in our study on language switching in a recognition task. Taken together, the absence of direct correlations among equivalent measures in domainspecific language and domain-general cognitive control does not imply that there is no overlap between the two domains. Our results suggest that this overlap between language and domain-general control may manifest itself by a correlation between two measures that are not equivalent across domains, such as global response times on the Simon task and the switch effect in a bilingual recognition task.

The results of this study cannot be easily integrated into current theories of language switches in production (Green, 1998; Schneider \& Anderson, 2010), but urge the need for a specific framework on language switches in recognition. The inhibitory control model (Green, 1998) suggests inhibitory control involvement in switching from L2 into L1; a hypothesis which seems to be corroborated by the previously reported interaction between the Simon effect and backward switching in mixed-language picture naming (Linck et al., 2012). However, we did not find the same correlation on a bilingual categorisation task. Domain-general inhibitory control as measured by performance on the Simon task was not related to backward switch costs, but only to forward switch costs. Thus, from our understanding the inhibitory control cannot account for this pattern. The same applies to the sequential difficulty hypothesis (Schneider \& Anderson, 2010), which suggests increased switch costs after difficult (in this context, L2) trials. Again, this theoretical 
framework can explain the difficulty of switching from an L2 into a L1 or the difficulty of repeating a difficult trial, but it cannot explain an interaction between L2-switches and domain-general control because L2-switches follow easy (L1-)trials.

A better understanding of the interaction between global response times on the Simon task and bilingual language processing can be achieved by considering the impressive amount of studies on a so-called bilingual advantage in Simon task performance (for a recent review, see Zhou \& Krott, 2016). While some studies have revealed bilingual advantages on the conflict effect in non-verbal conflict tasks specifically (Bialystok, Craik \& Luk, 2008; Bialystok, Craik, Grady, Chau, Ishii, Gunji \& Pantev, 2005; Bialystok, Craik, Klein \& Viswanathan, 2004; Poarch \& van Hell, 2012; Salvatierra \& Rosselli, 2011; Tse \& Altarriba, 2014), others have found a combination of overall better performance and a reduced conflict effect (Bialystok, Craik \& Ryan, 2006; Costa, Hernandez \& Sebastian-Galles, 2008) or only overall better performance (Bialystok, 2006; Coderre \& van Heuven, 2014; Costa et al., 2009; Martin-Rhee \& Bialystok, 2008; Struys, Mohades, Bosch \& van den Noort, 2015). Interestingly, overall better performance for bilinguals on the Simon task is only found in high-monitoring conditions with an equal percentage of congruent and incongruent trials (see also Costa et al., 2009), which is exactly the same version as the one used in the present study. Our results suggest that an L2-switch in a bilingual categorisation task taps into the same monitoring requirements as a Simon task with as many congruent as incongruent trials.

Our results support instead a monitoring account of language switching in recognition tasks. In this account, the monitor has the same function as in a Simon task in that it keeps track of the probability of a switch on the subsequent trial based on the congruency of the previous trials and it regulates the activation level of the two mental language systems accordingly. One of the major roles of this monitor is to alleviate the behavioural costs associated with these switches (Botvinick, Braver, Barch, Carter \& Cohen, 2001); as a result, the behavioural effects of the monitor's efficiency are expected to manifest themselves most on the trial type that creates the largest behavioural cost. On a language task with mixed-language stimuli, the most challenging trials are the switch trials, and arguably even more so the switches from easy trials (words in the dominant language) to difficult trials (words in the non-dominant language) than the switches in the inverse direction. Therefore, individuals with a more efficient monitor will show a lower switch effect, especially on switches from L1 into L2. The monitor is assumed to operate on a trial-by-trial basis, which means that it assesses the need for adapting the activation level of each mental language system based on the distribution of these two systems over the previous trials. In a mixedlanguage task, the probability of the next trial being a costly L2-switch is evidently higher on an L1-trial (and even more so on a L1-repeat trial) than on an L2-trial (in which case it is zero). Thus, on an L1-repeat trial, the monitor signals a high probability of an upcoming L2-switch and increases the activation level of the L2 mental system. As a result, more strongly activated L2items may enter into competition with the L1-items, which may slow down performance on L1-repeat trials, as shown by the negative correlation between forward and backward switching costs. On an L2-switch trial, in contrast, the monitor decreases the activation levels of the L2 mental system because of the impossibility of a subsequent L2switch. This leads to overall higher error rates on L2repeat trials; and in some individuals, this can lead to higher response latencies on L2-switch than L2-repeat trials.

The absence of correlations between equivalent backward and forward switch measures of both tasks suggests that the monitor has a different function when stimulus-response compatibility is being manipulated, as is the case in the Simon task. On backward and forward switch trials in a mixed-language recognition task, participants have to switch between two mental language sets, composed of distinct stimuli (words in L1 and L2). Switch trials in the Simon task, however, do not involve a switch between two stimuli sets, but between an automatic response and the suppression of that response. In fact, our version of the Simon task was only composed of two different stimuli of the same difficulty (a colored square) that could appear on both sides of the presentation screen. As a result, the monitor's function was not to adapt the activation levels of these stimuli (as during the categorisation task), but to assess the probability of an upcoming stimulus-response conflict. While the usage of different stimuli for each of the two languages in the recognition task supposedly led to triallevel monitoring effects, the usage of the same stimuli for both congruent and incongruent trials only resulted in global monitoring effects. This means that monitoring requirements were constant throughout the entire Simon task, which consisted of an equal number of congruent and incongruent trials, and unpredictable switches between both trial types.

The monitoring account suggests a connection between the monitoring requirements of a task in terms of the distribution of the trial types and the engagement of the monitor, leading to behavioural effects on specific trial types. Therefore, one of the main limitations of the present study is that we only included two experimental tasks with an equal distribution of switch and repeat trials (for the language task) and of congruent and incongruent trials (for the Simon task). The need for monitoring in this type of tasks is particularly high; hence, we 
suggest that a manipulation of this distribution could change the observed effects. The monitoring account of language switching in recognition tasks makes two testable predictions with regard to these effects: first, it predicts significantly higher forward switching costs and no negative correlation between forward and backward switching costs on language switching tasks with lower monitoring requirements (for instance, with only $25 \%$ of L2-trials); second, it assumes no relationship between forward switching costs in language recognition tasks and global response times on low-monitoring versions of the Simon task with an unequal distribution of congruent and incongruent trials (for instance, with only $25 \%$ of incongruent trials).

Further studies should investigate whether the proposed monitoring account only applies to recognition or also to mixed-language production tasks. Interestingly, some of the previous studies on bilingual production that could not find a relation between switch costs in tasks of language and domain-general cognitive control have reported significant correlations between mixing costs in these two domains (Cattaneo, Calabria, Marne, Gironell, Abutalebi \& Costa, 2015; Prior \& Gollan, 2013). While switch costs are generally seen as indices of reactive or inhibitory control, mixing costs are considered to reflect proactive control or monitoring. Based on these findings, it can thus be assumed that monitoring and not inhibitory control is the overlapping mechanism between the two domains.

\section{The effects of language proficiency and exposure on language switching and cognitive control}

The results from this study lend some support to the adaptive control hypothesis (Green \& Abutalebi, 2013), which predicts adaptability of language control processes in response to changing interactional contexts. A crucial question in this respect is whether the strength of language control networks in individual language users shows shortterm adaptation as a function of the dynamics of language use patterns or rather long-term adaptation related to the length of active bilingualism. Interestingly, our results show crucial differences in the impact of several language background variables on the speed of L 2 word processing, and on the switch costs. In line with our hypothesis, the L2-effect on response times in the bilingual categorisation task was significantly and positively correlated with the age of L2 acquisition; and significantly and negatively correlated with self-rated L2 proficiency, L2 exposure, and L2 verbal fluency. In contrast to our hypothesis, the switch effect on response times showed a selective correlation with L2 exposure but not with any of the other language background measures. In fact, individuals with higher levels of recent exposure to their second language showed a lower cost of switching from the dominant into the non-dominant language than those with lower exposure to the language. The remarkably selective correlation with exposure may be explained by the specific characteristics of our group of participants: as students of French linguistics in a bilingual city, they come from various linguistic situations at home. In order for those students with lower skills in French to catch up with their near-native peers, additional foreign language classes were strongly encouraged, as a result of which students with lower levels of second language proficiency or a later onset age of second language acquisition may still show a higher percentage of recent language exposure. Crucially, the size of the forward switch cost thus did not depend on the onset age of acquisition or level of second language proficiency but on the exposure to the language over the previous year, suggesting high adaptability of this language control ability.

These results are in line with previous studies showing an interaction between patterns of language use and cognitive control (Hartanto \& Yang, 2016; Verreyt et al., 2016; Yang et al., 2016). Remarkably, these studies have tested the adaptive (language) control hypothesis by investigating how bilinguals process domain-general control tasks. In line with the results of the present study, we suggest that these effects can be explained by domaingeneral involvement in language switching, as revealed by the dependency between forward language switching costs and global response times on the Simon task. One of the limitations of the current study is that domain-specific and domain-general control abilities were measured at one time point only. A longitudinal research design with an experimental manipulation of language exposure in two or more groups could reveal if domain-general control abilities are indeed highly responsive to changes in the linguistic environment.

\section{Conclusion}

The present study collected measures of domaingeneral cognitive and domain-specific language control in a sample of bilingual young adults with varying levels of second language proficiency, onset ages of acquisition, and exposure rates. Our results show domaingeneral monitoring involvement in specific components of language switching performance, and a contribution of language exposure to these specific language control measures. The present study thus adds to a growing of body of literature on the plasticity of control functions in the bilingual mind. We believe that the field of cognitive control in bilinguals may benefit from these research designs because they can reveal exactly which aspects of the bilingual experience rely on domain-general control and to what extent these functions can be trained as a function of language experience. 


\section{Appendix 1. Results from the two-way analysis of variance on accuracy scores of the mixed-language categorisation task.}

As for the by-subject analyses (F1), we found a highly significant effect of Language on the accuracy scores (see Figure 2), $F 1(1,31)=45.83, p<.001, \eta \mathrm{p} 2=.60$; but we found no main effect of Type of trial. We found a nearly significant interaction effect between the variables Language and Type of trial, $F 1(1,31)=3.62, p=.07$, $\eta \mathrm{p} 2=.10$. The by-item analyses (F2) on response times confirmed the $\mathrm{F} 1$ analyses, with a highly significant main effect of Language, $F 2(1,151)=116.11, p<.001, \eta \mathrm{p} 2$ $=.52$; no significant main effect of Type of trial, $F 2(1$, $151)=0.84, p$ ns.; and no significant interaction effect between Language and Type of trial, $F 2(1,151)=1.73$, $p$ ns.

\section{References}

Abutalebi, J., \& Green, D. W. (2008). Control mechanisms in bilingual language production: Neural evidence from language switching studies. Language and Cognitive Processes, 23(4), 557-582. doi:10.1080/01690960801920602

Baayen, R. H., Piepenbrock, R., \& Van Rijn, H. (1993). The CELEX lexical database (CD-ROM). Philadelphia: University of Pennsylvania, Linguistic Data Consortium.

Babcock, L., \& Vallesi, A. (2015). Language control is not a onesize-fits-all languages process: evidence from simultaneous interpretation students and the n-2 repetition cost. Frontiers in Psychology, 6. doi:10.3389/fpsyg.2015.01622

Bialystok, E. (2006). Effect of bilingualism and computer video game experience on the Simon task. Canadian Journal of Experimental Psychology-Revue Canadienne De Psychologie Experimentale, 60(1), 68-79. doi:10.1037/cjep2006008

Bialystok, E., Craik, F., \& Luk, G. (2008). Cognitive control and lexical access in younger and older bilinguals. Journal of Experimental Psychology-Learning Memory and Cognition, 34(4), 859-873. doi:10.1037/0278-7393.34.4.859

Bialystok, E., Craik, F. I. M., Grady, C., Chau, W., Ishii, R., Gunji, A., \& Pantev, C. (2005). Effect of bilingualism on cognitive control in the Simon task: evidence from MEG. Neuroimage, 24(1), 40-49. doi:10.1016/j.neuroimage.2004.09.044

Bialystok, E., Craik, F. I. M., Klein, R., \& Viswanathan, M. (2004). Bilingualism, aging, and cognitive control: Evidence from the Simon task. Psychology and Aging, 19(2), 290-303. doi:10.1037/0882-7974.19.2.290

Bialystok, E., Craik, F. I. M., \& Ryan, J. (2006). Executive control in a modified antisaccade task: Effects of aging and bilingualism. Journal of Experimental PsychologyLearning Memory and Cognition, 32(6), 1341-1354. doi:10.1037/0278-7393.32.6.1341

Blais, C., Stefanidi, A., \& Brewer, G. A. (2014). The Gratton effect remains after controlling for contingencies and stimulus repetitions. Frontiers in Psychology, 5, 1-11. doi:10.3389/fpsyg.2014.01207
Bobb, S. C., Wodniecka, Z., \& Kroll, J. F. (2013). What bilinguals tell us about cognitive control: Overview to the special issue. Journal of Cognitive Psychology, 25(5), 493496. doi:10.1080/20445911.2013.822724

Botvinick, M. M., Braver, T. S., Barch, D. M., Carter, C. S., \& Cohen, J. D. (2001). Conflict monitoring and cognitive control. Psychological Review, 108(3), 624-652. doi:10.1037//0033-295x.108.3.624

Branzi, F. M., Calabria, M., Boscarino, M. L., \& Costa, A. (2016). On the overlap between bilingual language control and domain-general executive control. Acta Psychologica, 166, 21-30. doi:10.1016/j.actpsy.2016.03.001

Calabria, M., Branzi, F. M., Marne, P., Hernandez, M., \& Costa, A. (2015). Age-related effects over bilingual language control and executive control. Bilingualism-Language and Cognition, 18(1), 65-78. doi:10.1017/s1366728913000138

Calabria, M., Hernandez, M., Branzi, F. M., \& Costa, A. (2012). Qualitative differences between bilingual language control and executive control: evidence from task-switching. Frontiers in Psychology, 3. doi:10.3389/fpsyg.2011.00399

Cattaneo, G., Calabria, M., Marne, P., Gironell, A., Abutalebi, J., \& Costa, A. (2015). The role of executive control in bilingual language production: A study with Parkinson's disease individuals. Neuropsychologia, 66, 99-110. doi:10.1016/j.neuropsychologia.2014.11.006

Coderre, E. L., \& van Heuven, W. J. B. (2014). The effect of script similarity on executive control in bilinguals. Frontiers in Psychology, 5. doi:10.3389/fpsyg.2014.01070

Costa, A., Hernandez, M., Costa-Faidella, J., \& SebastianGalles, N. (2009). On the bilingual advantage in conflict processing: Now you see it, now you don't. Cognition, 113(2), 135-149. doi:10.1016/j.cognition.2009.08.001

Costa, A., Hernandez, M., \& Sebastian-Galles, N. (2008). Bilingualism aids conflict resolution: Evidence from the ANT task. Cognition, 106(1), 59-86. doi:10.1016/j.cognition.2006.12.013

Costa, A., \& Santesteban, M. (2004). Lexical access in bilingual speech production: Evidence from language switching in highly proficient bilinguals and L2 learners. Journal of Memory and Language, 50(4), 491-511. doi:10.1016/j.jml.2004.02.002

Costa, A., Santesteban, M., \& Cano, A. (2005). On the facilitatory effects of cognate words in bilingual speech production. Brain and Language, 94(1), 94-103. doi:10.1016/j.band1.2004.12.002

Costa, A., Santesteban, M., \& Ivanova, I. (2006). How do highly proficient bilinguals control their lexicalization process? Inhibitory and language-specific selection mechanisms are both functional. Journal of Experimental PsychologyLearning Memory and Cognition, 32(5), 1057-1074. doi:10.1037/0278-7393.32.5.1057

Declerck, M., \& Philipp, A. M. (2015). A review of control processes and their locus in language switching. Psychonomic Bulletin \& Review, 22(6), 1630-1645. doi:10.3758/s13423-015-0836-1

Dijkstra, T., \& van Heuven, W. J. B. (2002). The architecture of the bilingual word recognition system: From identification to decision. Bilingualism-Language and Cognition, 5(3), 175-197. doi:10.1017/s1366728902003012 
Durlik, J., Szewczyk, J., Muszynski, M., \& Wodniecka, Z. (2016). Interference and Inhibition in Bilingual Language Comprehension: Evidence from PolishEnglish Interlingual Homographs. Plos One, 11(3). doi:10.1371/journal.pone.0151430

Festman, J., \& Munte, T. F. (2012). Cognitive control in Russian-German bilinguals. Frontiers in Psychology, 3. doi:10.3389/fpsyg.2012.00115

Fink, A., \& Goldrick, M. (2015). Pervasive benefits of preparation in language switching. Psychonomic Bulletin \& Review, 22(3), 808-814. doi:10.3758/s13423-014-0739-6

Garbin, G., Sanjuan, A., Forn, C., Bustamante, J. C., Rodriguez-Pujadas, A., Belloch, V., Hernandez, M., Costa, A., \& Avila, C. (2010). Bridging language and attention: Brain basis of the impact of bilingualism on cognitive control. NeuroImage, 53(4), 1272-1278. doi:10.1016/j.neuroimage.2010.05.078

Gollan, T. H., \& Ferreira, V. S. (2009). Should I Stay or Should I Switch? A Cost-Benefit Analysis of Voluntary Language Switching in Young and Aging Bilinguals. Journal of Experimental Psychology-Learning Memory and Cognition, 35(3), 640-665. doi:10.1037/a0014981

Gollan, T. H., \& Goldrick, M. (2016). Grammatical constraints on language switching: Language control is not just executive control. Journal of Memory and Language, 90, 177-199. doi:10.1016/j.jml.2016.04.002

Gray, T., \& Kiran, S. (2016). The relationship between language control and cognitive control in bilingual aphasia. Bilingualism-Language and Cognition, 19(3), 433-452. doi:10.1017/s1366728915000061

Green, D. W. (1998). Mental control of the bilingual lexicosemantic system. Bilingualism: Language and Cognition, 1(2), 67-81. doi:10.1017/s1366728998000133

Green, D. W., \& Abutalebi, J. (2013). Language control in bilinguals: The adaptive control hypothesis. Journal of Cognitive Psychology, 25(5), 515-530. doi:10.1080/20445911.2013.796377

Hartanto, A., \& Yang, H. (2016). Disparate bilingual experiences modulate task-switching advantages: A diffusion-model analysis of the effects of interactional context on switch costs. Cognition, 150, 10-19. doi:10.1016/j.cognition.2016.01.016

Hilchey, M. D., \& Klein, R. M. (2011). Are there bilingual advantages on nonlinguistic interference tasks? Implications for the plasticity of executive control processes. Psychonomic Bulletin \& Review, 18(4), 625658. doi:10.3758/s13423-011-0116-7

Ivanova, I., Murillo, M., Montoya, R. I., \& Gollan, T. H. (2016). Does bilingual language control decline in older age? Linguistic Approaches to Bilingualism, 6(1-2), 86-118. doi:10.1075/lab.15003.iva

Ivanova, I., Salmon, D. P., \& Gollan, T. H. (2014). Which Language Declines More ? Longitudinal versus Cross-sectional Decline of Picture Naming in Bilinguals with Alzheimer's Disease. Journal of the International Neuropsychological Society, 20(5), 534-546. doi:10.1017/s1355617714000228

Jackson, G., Swainson, R., Cunnington, R., \& Jackson, S. (2001). ERP correlates of executive control in language-switching. Neuroimage, 13(6), S322-S322.
Jaeger, T. F. (2008). Categorical data analysis: Away from ANOVAs (transformation or not) and towards logit mixed models. Journal of Memory and Language, 59(4), 434-446. doi:10.1016/j.jml.2007.11.007

Kleinman, D., \& Gollan, T. H. (2016). Speaking Two Languages for the Price of One: Bypassing Language Control Mechanisms via Accessibility-Driven Switches. Psychological Science, 27(5), 700-714. doi:10.1177/0956797616634633

Kroll, J. F., \& Bialystok, E. (2013). Understanding the consequences of bilingualism for language processing and cognition. Journal of Cognitive Psychology, 25(5), 497514. doi:10.1080/20445911.2013.799170

Lemhofer, K., Dijkstra, T., \& Michel, M. C. (2004). Three languages, one ECHO: Cognate effects in trilingual word recognition. Language and Cognitive Processes, 19(5), 585-611. doi:10.1080/016909604444000007

Levelt, W. J. M., Roelofs, A., \& Meyer, A. S. (1999). A theory of lexical access in speech production. Behavioral and Brain Sciences, 22(1), 1-+.

Linck, J. A., Schwieter, J. W., \& Sunderman, G. (2012). Inhibitory control predicts language switching performance in trilingual speech production. Bilingualism-Language and Cognition, 15(3), 651-662. doi:10.1017/s136672891100054x

Liu, H. H., Liang, L. J., Dunlap, S., Fan, N., \& Chen, B. G. (2016). The effect of domain-general inhibition-related training on language switching: An ERP study. Cognition, 146, 264-276. doi:10.1016/j.cognition.2015.10.004

Macizo, P., Bajo, T., \& Paolieri, D. (2012). Language switching and language competition. Second Language Research, 28(2), 131-149. doi:10.1177/0267658311434893

Magezi, D. A., Khateb, A., Mouthon, M., Spierer, L., \& Annoni, J. M. (2012). Cognitive control of language production in bilinguals involves a partly independent process within the domain-general cognitive control network: Evidence from task-switching and electrical brain activity. Brain and Language, 122(1), 55-63. doi:10.1016/j.band1.2012.04.008

Marian, V., Blumenfeld, H. K., \& Kaushanskaya, M. (2007). The Language Experience and Proficiency Questionnaire (LEAP-Q): Assessing language profiles in bilinguals and multilinguals. Journal of Speech Language and Hearing Research, 50(4), 940-967. doi:10.1044/1092-4388(2007/067)

Martin, C. D., Strijkers, K., Santesteban, M., Escera, C., Hartsuiker, R. J., \& Costa, A. (2013). The impact of early bilingualism on controlling a language learned late: an ERP study. Frontiers in Psychology, 4. doi:10.3389/fpsyg.2013.00815

Martin-Rhee, M. M., \& Bialystok, E. (2008). The development of two types of inhibitory control in monolingual and bilingual children. Bilingualism-Language and Cognition, 11(1), 81-93. doi:10.1017/s1366728907003227

Meuter, R. F. I., \& Allport, A. (1999). Bilingual language switching in naming: Asymmetrical costs of language selection. Journal of Memory and Language, 40(1), 2540. doi:10.1006/jmla.1998.2602

Miyake, A., Friedman, N. P., Emerson, M. J., Witzki, A. H., Howerter, A., \& Wager, T. D. (2000). The 
unity and diversity of executive functions and their contributions to complex "frontal lobe" tasks: A latent variable analysis. Cognitive Psychology, 41(1), 49-100. doi:10.1006/cogp.1999.0734

Orfanidou, E., \& Sumner, P. (2005). Language switching and the effects of orthographic specificity and response repetition. Memory \& Cognition, 33(2), 355-369. doi:10.3758/bf03195323

Paap, K. R., \& Greenberg, Z. I. (2013). There is no coherent evidence for a bilingual advantage in executive processing. Cognitive Psychology, 66(2), 232-258. doi:10.1016/j.cogpsych.2012.12.002

Philipp, A. M., Gade, M., \& Koch, I. (2007). Inhibitory processes in language switching: Evidence from switching language-defined response sets. European Journal of Cognitive Psychology, 19(3), 395-416. doi:10.1080/09541440600758812

Poarch, G. J., \& van Hell, J. G. (2012). Executive functions and inhibitory control in multilingual children: Evidence from second-language learners, bilinguals, and trilinguals. Journal of Experimental Child Psychology, 113(4), 535551. doi:10.1016/j.jecp.2012.06.013

Prior, A., \& Gollan, T. H. (2011). Good Language-Switchers are Good Task-Switchers: Evidence from SpanishEnglish and Mandarin-English Bilinguals. Journal of the International Neuropsychological Society, 17(4), 682-691. doi: $10.1017 / \mathrm{s} 1355617711000580$

Prior, A., \& Gollan, T. H. (2013). The elusive link between language control and executive control: A case of limited transfer. Journal of Cognitive Psychology, 25(5), 622-645. doi:10.1080/20445911.2013.821993

Reynolds, M. G., Schloffel, S., \& Peressotti, F. (2016). Asymmetric Switch Costs in Numeral Naming and Number Word Reading: Implications for Models of Bilingual Language Production. Frontiers in Psychology, 6. doi:10.3389/0asvg.2015.02011

Salvatierra, J. L., \& Rosselli, M. (2011). The effect of bilingualism and age on inhibitory control. International Journal of Bilingualism, 15(1), 26-37. doi:10.1177/1367006910371021

Schneider, D. W., \& Anderson, J. R. (2010). Asymmetric switch costs as sequential difficulty effects. Quarterly Journal of Experimental Psychology, 63(10), 1873-1894. doi:10.1080/17470211003624010

Simon, J. R., \& Rudell, A. P. (1967). Auditory S-R compatibility - Effect of an irrelevant cue on information processing. Journal of Applied Psychology, 51(3), 300-\&. doi: $10.1037 / \mathrm{h} 0020586$

Singh, N., \& Mishra, R. K. (2015). The modulatory role of second language proficiency on performance monitoring: evidence from a saccadic countermanding task in high and low proficient bilinguals. Frontiers in Psychology, 5. doi:10.3389/fpsyg.2014.01481

Starreveld, P. A., De Groot, A. M. B., Rossmark, B. M. M., \& Van Hell, J. G. (2014). Parallel language activation during word processing in bilinguals: Evidence from word production in sentence context. Bilingualism-Language and Cognition, 17(2), 258-276. doi:10.1017/s1366728913000308
Struys, E., Mohades, G., Bosch, P., \& van den Noort, M. (2015). Cognitive Control in Bilingual Children Disentangling the Effects of Second-Language Proficiency and Onset Age of Acquisition. Swiss Journal of Psychology, 74(2), 65-73. doi:10.1024/1421-0185/a000152

Thomas, M. S. C., \& Allport, A. (2000). Language switching costs in bilingual visual word recognition. Journal of Memory and Language, 43(1), 44-66. doi:10.1006/jmla.1999.2700

Tse, C. S., \& Altarriba, J. (2014). The relationship between language proficiency and attentional control in CantoneseEnglish bilingual children: evidence from Simon, Simon switching, and working memory tasks. Frontiers in Psychology, 5. doi:10.3389/fpsyg.2014.00954

Tse, C. S., \& Altarriba, J. (2015). Local and Global Task Switching Costs in Bilinguals Who Vary in Second Language Proficiency. American Journal of Psychology, 128(1), 89-106. doi:10.5406/amerjpsyc.128.1.0089

Van Assche, E., Duyck, W., \& Gollan, T. H. (2013). WholeLanguage and Item-Specific Control in Bilingual Language Production. Journal of Experimental PsychologyLearning Memory and Cognition, 39(6), 1781-1792. doi: $10.1037 / \mathrm{a} 0032859$

van Heuven, W. J. B., Dijkstra, T., \& Grainger, J. (1998). Orthographic neighborhood effects in bilingual word recognition. Journal of Memory and Language, 39(3), 458483. doi:10.1006/jmla.1998.2584

van Maanen, L., \& van Rijn, H. (2010). The Locus of the Gratton Effect in Picture-Word Interference. Topics in Cognitive Science, 2(1), 168-180. doi:10.1111/j.1756-8765.2009.01069.x

Verhoef, K., Roelofs, A., \& Chwilla, D. J. (2009). Role of inhibition in language switching: Evidence from eventrelated brain potentials in overt picture naming. Cognition, 110(1), 84-99. doi:10.1016/j.cognition.2008.10.013

Verreyt, N., Woumans, E., Vandelanotte, D., Szmalec, A., \& Duyck, W. (2016). The influence of language-switching experience on the bilingual executive control advantage. Bilingualism-Language and Cognition, 19(1), 181-190. doi:10.1017/s1366728914000352

von Bastian, C. C., Souza, A. S., \& Gade, M. (2016). No Evidence for Bilingual Cognitive Advantages: A Test of Four Hypotheses. Journal of Experimental Psychology-General, 145(2), 246-258. doi:10.1037/xge0000120

von Studnitz, R. E., \& Green, D. W. (2002). The cost of switching language in a semantic categorization task. Bilingualism-Language and Cognition, 5(3), 241-251. doi:10.1017/s1366728902003036

Weissberger, G. H., Wierenga, C. E., Bondi, M. W., \& Gollan, T. H. (2012). Partially Overlapping Mechanisms of Language and Task Control in Young and Older Bilinguals. Psychology and Aging, 27(4), 959-974. doi: $10.1037 / \mathrm{a} 0028281$

Woumans, E., Ceuleers, E., Van der Linden, L., Szmalec, A., \& Duyck, W. (2015). Verbal and Nonverbal Cognitive Control in Bilinguals and Interpreters. Journal of Experimental Psychology-Learning Memory and Cognition, 41(5), 15791586. doi:10.1037/xlm0000107 
Yang, H. J., Hartanto, A., \& Yang, S. J. (2016). The Complex Nature of Bilinguals' Language Usage Modulates Task-Switching Outcomes. Frontiers in Psychology, 7. doi:10.3389/fpsyg.2016.00560

Yow, W. Q., \& Li, X. Q. (2015). Balanced bilingualism and early age of second language acquisition as the underlying mechanisms of a bilingual executive control advantage: why variations in bilingual experiences matter. Frontiers in Psychology, 6. doi:10.3389/fpsyg.2015.00164
Zhang, H. Y., Kang, C. Y., Wu, Y. J., Ma, F. Y., \& Guo, T. M. (2015). Improving proactive control with training on language switching in bilinguals. Neuroreport, 26(6), 354-359. doi:10.1097/wnr. 0000000000000353

Zhou, B. N., \& Krott, A. (2016). Data trimming procedure can eliminate bilingual cognitive advantage. Psychonomic Bulletin \& Review, 23(4), 1221-1230. doi:10.3758/s13423-015-0981-6 